\title{
Detection of shallow Aquifers Using Vertical Electrical Sounding in Abua Town, Rivers State, Nigeria
}

\author{
P.O. Eke $^{1 *} \&$ G. Ekpelu ${ }^{2}$ \\ ${ }^{I *}$ Reader, Department of Physics, Ignatius Ajuru University of Education, Port Harcourt, Nigeria. Email: peter.eke@iaue.edu.ng \\ ${ }^{2}$ Postgraduate Student, Department of Physics, Ignatius Ajuru University of Education, Port Harcourt, Nigeria.
}

Copyright: $\odot 2021$ P.O.Eke \& G.Ekpelu. This is an open access article distributed under the terms of the Creative Commons Attribution License, which permits unrestricted use, distribution, and reproduction in any medium, provided the original author and source are credited.

\section{ABSTRACT}

Eight Vertical Electrical Sounding surveys were carried out in Abua town in Rivers State, Nigeria to determine the depth to shallow aquifers suitable for borehole drilling for groundwater use in the town. The Schlumberger array method was employed with current electrode spread of $200 \mathrm{~m}$ to 600 $m$ and the corresponding electric current and voltage measured. The apparent resistivity was obtained and plotted against half the current electrode spread with the aid of an IPWIN 12 software to obtain the field curves which were interpreted in terms of resistivity, thickness and depth of occurrence. The results revealed two to four geoelectric sections with resistivity values of $8.29 \Omega$ to $777 \Omega$. The maximum depth penetrated was 56.5 $m$ with the maximum current electrode spread used. A shallow aquifer close to the surface at Omelema waterside was observed with a thickness of 49 $m$. The abnormal resistivity value of this zone indicates that it was probably contaminated by saline water intrusion. At Abua LGA site, a shallow aquifer was also observed at a depth of $7.86 \mathrm{~m}$. At the dump site, the shallow aquifer was contaminated by leachates while at Omelema primary school site the result revealed unconsolidated sediments. The results for Abua Amp site and Rghom site also revealed shallow aquifers at depths of 4 $m$ and $6 m$ respectively.

Keywords: Shallow aquifer, Vertical electrical sounding, Groundwater, Resistivity, Sounding curves.

\section{Introduction}

Vertical Electrical Sounding (VES) is a powerful tool for delineation of shallow groundwater aquifers and near-surface characterization. The is because it determines the extent to which formations resist the flow of electric current in the earth that occurs through a combination of ohmic, dielectric and electrolytic effects [1]. Practically, it provides a vertical profile that indicates the heterogeneities in the subsurface through the variation of subsurface resistivity affected by a lot of factors of which the presence of groundwater is one.

Groundwater naturally is found in soils, sands and cracks in rocks called aquifers. According to [2] the resistivity of water saturated sediments, aquifers, is lower than the resistivity of solid basement rock and unsaturated sediments, but higher than resistivity of clayey materials. These can be determined by a VES because the electrical resistivity of rocks within the earth is due to the moisture content of the pores spaces within the rock or soil and some number of factors that include salinity, degree of saturation of the pore, clay content, number, size and shape of the joining pores and compaction factor [3]. Intrusions by leachates can also affect the resistivity of the subsurface soils [4].

Abua Town, in Rivers State Nigeria, is an urban city with an increasing population as more developments come into the area. Like any developing urban area it is faced with the challenges of meeting the demands of portable water supply and other environmental issues. The government has not been able to meet these challenges, hence individuals have resulted to self-help, like providing boreholes for themselves. Most of these are drilled without subsurface knowledge of the area and lack of information on the aquifer characteristics of the region.

Although the region lies in the Niger Delta region with some aquifers close to the surface [5] it is important to know the aquifer depths in the town and avoid blind drilling without basic information of the aquifer characteristics. More 
so, some areas in the town are used as solid waste dumpsites which with time will produce leachates that will pollute the shallow aquifers. It is therefore important that good aquifers are identified to avoid health challenges that will arise from the use of polluted ones. This work is aimed at identifying good shallow aquifers in the town using the VES method for groundwater supply.

\section{Location of the Study Area}

Abua Town is located in Abua/Odual Local Government area of Rivers State that is south-south of the Niger delta in Nigeria with GPS coordinates of Latitude 4.8298 and Longitude 6.5674 (Figure 1). According to [6] the Niger delta is located approximately between longitudes $5^{\circ} 00^{\prime}$ to $8^{\circ} 00^{\prime} \mathrm{E}$ and latitudes $4^{\circ} 00^{\prime}$ to $8^{\circ} 00^{\prime} \mathrm{N}$.

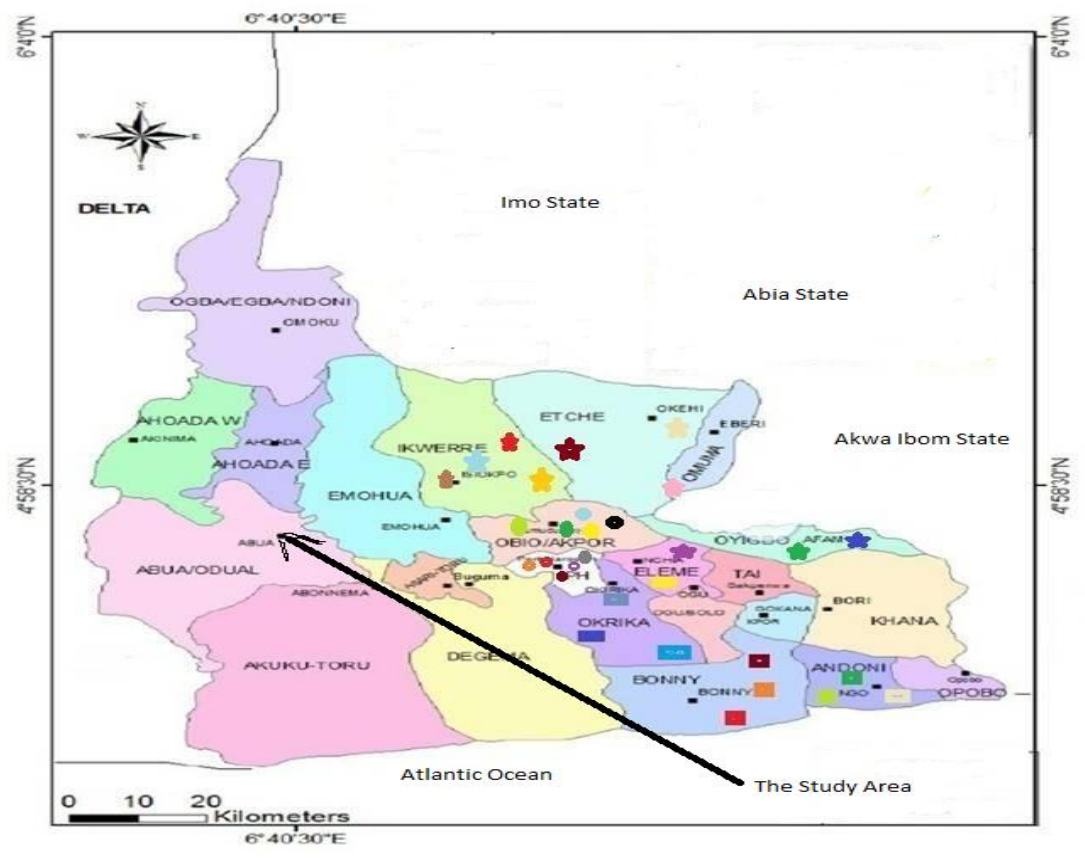

Fig.1. The Study Area [modified from 7]

Rivers State is south-south of the Niger delta and is one of the 36 states of the Federal Republic of Nigeria. It is bounded on the East by Akwa Ibom and Abia States, on the west by Bayelsa and Delta States and on the north by Imo State. The southern boundary is surrounded by the Atlantic Ocean. 50\% or more of the population live in the riverine areas where communities live in isolated barrier island, beaches, and other emergent land areas separated by tidal flats, channels and swamps [8]. Abua Local Government is in the western part of the state with a population of over two hundred and eighty thousand in a landmass of 704 square kilometers. The lack of potable water in this area is further compounded by saline water intrusion into fresh water aquifers in the coastal areas according to [5; 9 ; 10]. The regional geology of the study area lies within the Niger Delta of Nigeria that has been well described and documented by various authors [11]. The sedimentological evidence [12] suggests that the geometry of the delta has remained essentially the same since its inception. The stratigraphy consists of three major units of sediments classified from base to top as the Akata, Agbada and Benin Formations [13]. The top Benin formation is an extensive stratigraphic sedimentary basin with a variable thickness of up to $1,400 \mathrm{~m}$ in some parts [14]. It is predominantly sandy with a few clay and shale intercalation [12]. The sands are poorly cemented sandstones and are generally coarse-grained, with grains sub-angular to well round. The materials are believed to be deposited in a 
continental fluviatile to deltaic environment [14]. This formation is overlain by the coastal plain sands, deltaic plain sands, abandoned beach ridges, mangrove and freshwater swamps, meander belts and alluvium, and range in ages from Oligocene to Holocene [5].

\section{Theory}

According to Telford [15] the electrical resistivity method involves the use of electrical current introduced into the ground either naturally or by artificial means to study the variations of the electrical property of the subsurface formations. The fundamental electrical property of rock materials closely linked to their lithology according to Telford (1990) is their electrical resistivity which is a property that is a measure of the ability of materials to restrict the flow of electric current through them.

The moisture content of the pores spaces within a rock or soil salinity, degree of saturation of the pore, clay content, number, size and shape of the joining pores and compaction factor are all related in the Archie law [3];

$$
\rho_{\mathrm{e}}=\mathrm{a} \phi^{-\mathrm{m}} \mathrm{S}^{-\mathrm{n}} \rho_{\mathrm{w}}
$$

$\rho_{\mathrm{e}}$ is the resistivity of the rock, $\varphi$ is the porosity, $\mathrm{S}$ is the fraction of the pores containing water, $\rho_{\mathrm{w}}$ is the resistivity of water; and $\mathrm{a}, \mathrm{m}$ and $\mathrm{n}$ are empirical constants with values of $0.5 \leq \mathrm{a} \leq 2.5,1.3 \leq \mathrm{M} \leq 2.5$ and $\mathrm{n}=2$.

For two current electrodes at finite distance with their corresponding potential electrodes, the currents produced at both electrodes are hypothetically equal and act in opposite directions (from source to link) such that the resistivity of the subsurface is from Reynold [16] is;

$$
\rho=\mathrm{G} \frac{\nabla V}{I}
$$

Where $\mathrm{G}=2 \pi\left[\left(\frac{1}{r_{1}}-\frac{1}{r_{2}}\right)-\left(\frac{1}{r_{3}}-\frac{1}{r_{4}}\right)\right]$ is the Geometric factor.

Practically the quantities measured in a resistivity survey are the applied voltage and resultant current which are then used to obtain the resistivity above. $G$ is a function of the electrodes in the field data acquisition based on the array used.

In a homogenous and isotropic medium, the resistivity that will be measured and calculated from equation 2 will always have the exact value everywhere irrespective of the amount of current and electrode arrangement adopted in the data acquisition [15]. The equation also defines the real resistivity for a homogenous medium and for an inhomogeneous medium; it defines the apparent resistivity $\left(\rho_{\mathrm{a}}\right)$.

\section{Materials and Methods}

Eight sets of VES data were collected from eight locations using the Schlumberger array method of electrode spacing. A potential electrode spacing of 200 to $600 \mathrm{~m}$ was used to target the shallow aquifers and the current electrodes were adjusted accordingly. An ABEM Tetrameter was used to record the voltage and current and subsequently the resultant resistance, $R$ in ohms computed. The apparent resistivity values were inverted using IP12WIN resistivity sounding interpretation software to obtain the true resistivity, thickness and depths of the subsurface formations. 


\section{Results and Discussions}

Optimum The apparent resistivity, $\rho_{\mathrm{a}}$, values for each survey location computed from the field values and plotted against half the current electrode spread, $\mathrm{AB} / 2$, using IPWIN2 software produced the sounding curves of Figures 2(a) to (h) which gave the parameters of the geoelectric section; that is the layer resistivity, thickness and depth.

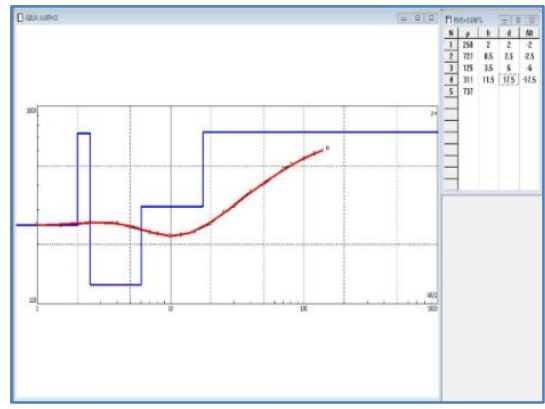

(a) Sounding Curve of Abua

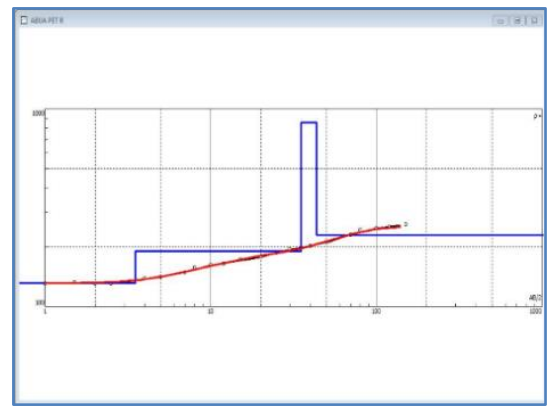

(c) Sounding Curve of Abua Pet Road

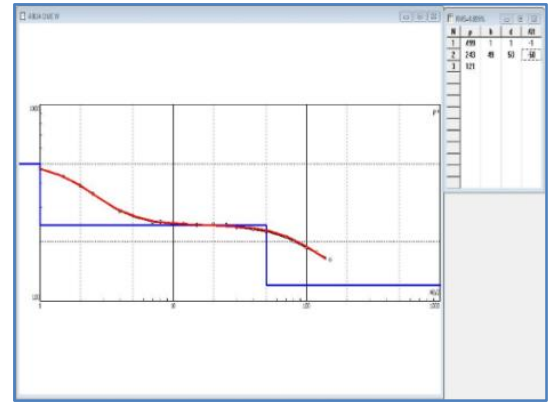

(e) Sounding Curve of Abua Omelema Waterside

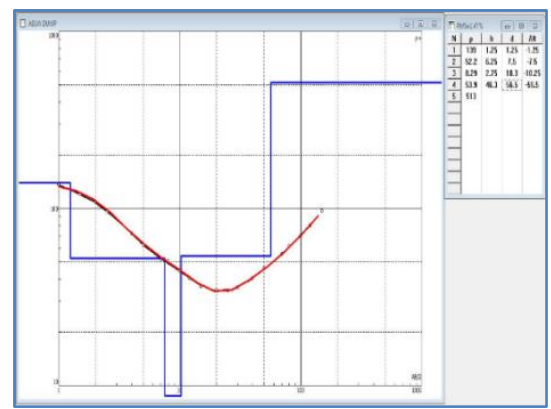

(g) Sounding Curve of Dumpsite Abua

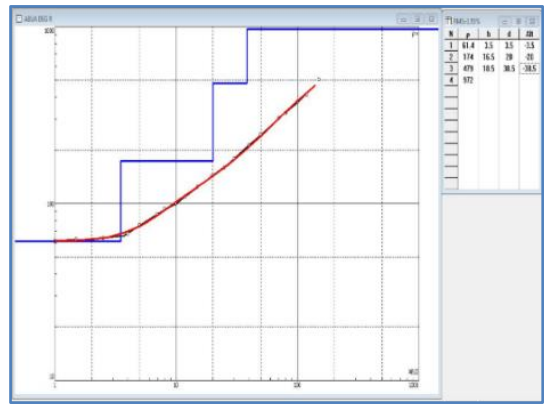

(b) Sounding Curve of Abua Degema Road

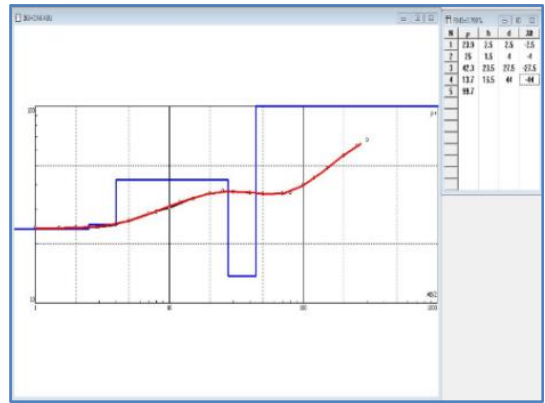

(d) Sounding Curve of Reghom Abua

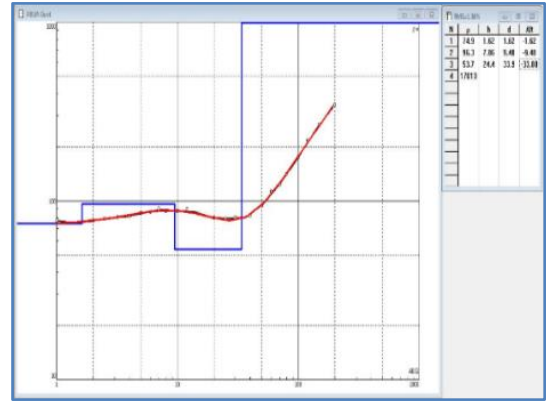

(f) Curve of Aboua Government Yard

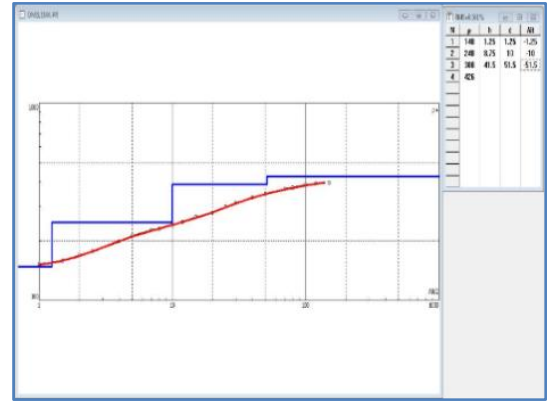

(h) Sounding Curve of Omelema Primary School

Fig.2. Sounding Curves for the various survey areas 
The summary of the sounding results for the various sites is presented in Table 1 .

Table 1. Sounding Curve Results.

\begin{tabular}{|c|c|c|c|}
\hline Location of Survey Site & $\rho / \Omega m$ & Thickness of Formation/m & Depth /m \\
\hline \multirow{3}{*}{ Abua Omelema Waterside } & 499 & 1.0 & 1.0 \\
\hline & 24 & 49.0 & 50.0 \\
\hline & 121 & - & - \\
\hline \multirow{4}{*}{ Abua Govt. } & 74.9 & 1.62 & 1.62 \\
\hline & 96.3 & 7.86 & 9.48 \\
\hline & 53.7 & 24.4 & 33.88 \\
\hline & 17013 & - & - \\
\hline \multirow{5}{*}{ Abua Dumpsite } & 139 & 1.25 & 1.25 \\
\hline & 52.2 & 6.25 & 7.5 \\
\hline & 8.29 & 2.75 & 10.3 \\
\hline & 53.9 & 46.3 & 56.5 \\
\hline & 51.3 & - & - \\
\hline \multirow{4}{*}{ Omelema Primary School } & 148 & 1.25 & 1.25 \\
\hline & 248 & 8.75 & 10.0 \\
\hline & 388 & 41.5 & 51.5 \\
\hline & 426 & - & - \\
\hline \multirow{5}{*}{ Abua Amp } & 250 & 2.0 & 2.0 \\
\hline & 727 & 0.5 & 2.5 \\
\hline & 125 & 3.5 & 6.0 \\
\hline & 311 & 11.5 & 17.5 \\
\hline & 737 & - & - \\
\hline \multirow{5}{*}{ Rghom } & 23.9 & 2.5 & 2.5 \\
\hline & 25.0 & 1.5 & 4.0 \\
\hline & 42.3 & 23.5 & 27.5 \\
\hline & 13.7 & 16.5 & 44.0 \\
\hline & 99.7 & - & - \\
\hline
\end{tabular}


The following interpretations can be inferred from the results of the soundings based on the resistivity values thickness, depth of occurrence and geology of the area. The maximum depth penetrated by the survey at the Abua Omelema waterside site is $50 \mathrm{~m}$ with two geoelectric sections of thickness $1.0 \mathrm{~m}$ and $49.0 \mathrm{~m}$. The depth of the third geoelectric section could not be reached because of the electrode spread. The resistivity values range from $24 \Omega \mathrm{m}$ to $499 \Omega \mathrm{m}$. In this site the second geoelectric section is an aquifer. However, it is probably contaminated by saline water intrusion from the salt water river as seen from its low resistivity compared to the upper layer with thickness of $1 \mathrm{~m}$ and high resistivity. A borehole within this section will provide contaminated portable water.

For the Abua LGA site, the maximum depth penetrated was $33.88 \mathrm{~m}$ with three geoelectric sections of $1.62 \mathrm{~m}, 7.86$ $\mathrm{m}$ and $24.4 \mathrm{~m}$. The resistivity values range from $53.7 \Omega \mathrm{m}$ to $96.3 \Omega \mathrm{m}$. Also the fourth geoelectric section could not be penetrated because of the current electrode spread. The fourth geoelectric section whose depth could not be reached had an abnormal resistivity of $17013 \Omega \mathrm{m}$. Based on the geoelectric section depths and thickness, the second section will be a good aquifer. The Abua Dumpsite has resistivity values of $139 \Omega \mathrm{m}$ in the top most formation and $53.9 \Omega \mathrm{m}$ for the fourth geoelectric section encountered. The maximum depth penetrated was $56.5 \mathrm{~m}$. The first geoelectric section is probably a clayey section from the resistivity value which is higher than the second section whose resistivity value has been drastically reduced by contamination probably from the leachates released from the solid dumpsite. Boreholes in this area for good groundwater can only be drilled at deeper depths as depths up to $10.3 \mathrm{~m}$ is already contaminated. In Omelema Primary School site, three geoelectric sections were penetrated with thickness of $1.25 \mathrm{~m}, 8.75 \mathrm{~m}$ and $43.5 \mathrm{~m}$. The maximum depth penetrated was $51.5 \mathrm{~m}$. This site has its resistivity value increasing steadily which indicates unsaturated sediments.

Abua Amp site has four geoelectric sections determined with thickness of $2.0 \mathrm{~m}, 0.5 \mathrm{~m}, 3.5 \mathrm{~m}$ and $11.5 \mathrm{~m}$ respectively. The maximum depth penetrated is $17.5 \mathrm{~m}$. Boreholes from depths above $6 \mathrm{~m}$ will be recommended. Rghom site has four geoelectric sections identified with thickness of $2.5 \mathrm{~m}, 1.5 \mathrm{~m}, 23.5 \mathrm{~m}$ and $16.5 \mathrm{~m}$ respectively. The maximum depth penetrated is $44 \mathrm{~m}$. At this site, boreholes can be drilled at depths above $4 \mathrm{~m}$.

\section{Conclusion}

The results of this work show that shallow aquifers are located at depths of from $4 \mathrm{~m}$ below the surface in some parts of Abua town. Close to the dumpsite site and the waterside, the aquifers are polluted by leachates and saline water intrusion respectively. The study results indicates that boreholes should be drilled targeting depths of more than $20 \mathrm{~m}$ to get good portable groundwater in Abua town, Rivers State, Nigeria.

\section{Declarations}

\section{Source of Funding}

This research did not receive any specific grant from funding agencies in the public, commercial, or not-for-profit sectors.

\section{Competing Interests Statement}

The authors declare no competing financial, professional and personal interests. 


\section{Consent for publication}

We declare that we consented for the publication of this research work.

\section{Availability of data and material}

Authors are willing to share data and material according to the relevant needs.

\section{References}

[1] E.S. Robinson, C. Coruh, Basic Exploration Geophysics. John Wiley \& Sons, Inc., Canada (1998).

[2] R, Kirch Groundwater Geophysics, A Tool for Hydrogeology, Springer-Verlag, Berlin Heidelberg (2009).

[3] W. Lowrie, Fundamentals of Geophysics. Cambridge University Press, UK (1997).

[4] P.O. Eke, B.U. Amechi, P. Umukoro, Electrical Resistivity Investigation of Solid Dumpsite at Ignatius Ajuru University of Education, Port Harcourt, Rivers State, Nigeria, International Journal of Science, Technology, Engineering and Science Education, 4(1), (2019) 08 -13.

[5] J.O Etu-Efeotor, E.G. Akpokodje, Aquifer Systems of Niger Delta. Journal of Mining and Geology, 26(2) (1990) 279-285.

[6] P.O. Eke P. Umukoro, Site Investigation of Subsurface Lithology of Ignatius Ajuru University of Education, Port Harcourt, Nigeria, Using Electrical Resistivity Methods, Asian Journal of Applied Science and Technology, 4(1), (2020) 139-146.

[7] Google Maps and MapHills (2020). Google Maps of Niger Delta, Nigeria and Africa. www.googlemaps.

Retrieved: $14 / 4 / 20$.

[8] Niger Delta Regional Development Master Plan, NDRDMP, Niger Delta Region and People: NDRDMP report. http://www.nddc.gov.ng/NDRDMP\%20chapter201., (2000) 49-99.

[9] L.C. Amajor, Geochemical Characteristics of Groundwater in Port Harcourt and Environs. Proceedings of NWASA Symp. Lagos (1986).

[10] T.G. Leton, Water and Waste Water Engineering. Celwill Nigeria Ltd. Lagos (2004).

[11] T.K.S. Abam, Soil Exploration and Foundations in the Recent Coastal Areas of Nigeria. Bulletin of the International Association of Engineering Geology, Paris (1986).

[12] K.C. Short, A.J. Stauble, Outline of geology of Niger Delta, American Association of Petroleum Geologist Bulletin, 51, (1967) 761-799.

[13] P.O Eke, Depositional Sequence and Lithostratigraphic Units of Southern Niger Delta, Nigeria, from Gamma Ray and Electric Logs, International Journal of Scientific \& Engineering Research 11(5), (2020) 102-107.

[14] A.C. Onyeagucha, Petrography and Depositional Environment of the Benin Formation. J. Min. Geol., 17 (1980) 23-31.

[15] W.N. Telford, L.P. Geldart, R.E. Sheriff, D.A Keys, Applied Geophysics. Cambridge Univ. Press UK (1990). [16] J.M. Reynolds, An Introduction to Applied and Environmental Geophysics. John Wiley and Sons, UK, (2011). 